\author{
P. M. S. Hacker \\ epeter.hacker@sjc.ox.ac.uk mail
}

\title{
Forms of Life
}

\section{Abstract}

The phrase 'Lebensform' (form of life) had a long and varied history prior to Wittgenstein's use of it on a mere three occasions in the Philosophical Investigations. It is not a pivotal concept in Wittgenstein's philosophy. But it is a minor signpost of a major reorientation of philosophy, philosophy of language and logic, and philosophy of mathematics that Wittgenstein instigated. For Wittgenstein sought to replace the conception of a language as a meaning calculus (Frege, Russell, the Tractatus) by an anthropological or ethnological conception. A language is not a class of sentences that can be formed from a set of axioms (definitions), formation and transformation rules and the meanings of which is given by their truth-conditions, but an open-ended series of interlocking language-games constituting a form of life or way of living (a culture). Wittgenstein's uses of 'Lebensform' and its cognates, both in the Investigations and in his Nachlass are severally analysed, and various exegetical misinterpretations are clarified.

\section{1. 'Forms of life'}

Wittgenstein's use of the expression 'Lebensform' has occasioned much controversy. It is not a theoretical term that Wittgenstein invented. Nor is it a theoretical term that others invented, if a theoretical term is one that belongs to an empirical theory and falls into obsolescence with the refutation of the theory, for example 'caloric' and 'phlogiston' that belonged to Stahl's mistaken theory of combustion. It is not a technical term, like 'truth-function' or 
'truth-value', for it is not a technical term at all. Moreover Wittgenstein did not invent it. It has a long history prior to his employment of the expression. That has now happily been traced by a number of scholars such as Jésus Padilla Gálvez, Margit Gaffal, Noberto Abreu e Silva Neto, and S. Helmreich and S. Roosth. ${ }^{1}$ The German expressions 'Lebensform' and 'Form des Lebens' appear to have originated around 1800. 'Lebensform' (and its plural) had a distinctive use in cosmology. Karl Eberhard Schelling published a book in 1806, in which he wrote of 'the life form of a heavenly body'. Physiologists such as Karl Friedrich Burdach (in 1838) and Johannes Müller (in 1840), used the expression to refer to biological and more specifically animal forms of life. Theodor Bischoff, an anatomist, wrote an article in 1836 on crocodiles in which he emphasized the dependence of the physiology of amphibians on their environment and their form of life, thus giving the term an ecological twist. Friedrich Schleiermacher, in his lectures on psychology (1830) shifted the term in the direction of psychology, using the term 'Lebensform' as a synonym of 'Lebenstypus', signifying personal character formation in relation to society. Wilhelm von Humboldt in his On Language (1836) linked the idea of forms of life with customs and habits of a language-using community. After Darwin, the expression was widely used to refer to biological species. So, there was a widespread and varied use of the expression in the nineteenth century.

The twentieth century added to these uses. Alfred Wechsler, writing in Austria under the pseudonym 'W. Fred', published an influential book Lebensformen: Anmerkungen über die Technik des gesellschaftlichen Lebens in 1905 (reviewed by von Hoffmannsthal). He made systematic use of the expression in discussing manners and mores of respectable society, ranging from fashion, forms of sociability, conversation, salons, to cooking, dining, sports, travel

\footnotetext{
${ }^{1}$ See, in Jésus Padilla Gálvez and Margit Gaffal eds. Forms of Life and Language Games (Ontos Verlag, Heusenstamm, 2011), Padilla Galvez, "Language as Forms of Life", Gaffal, "Forms of Life as Social Techniques", and Abreu e Silva Neto, "The Uses of 'Forms of Life' and the Meanings of Life"; and S. Helmreich and S. Roosth, "Life Forms: a Keyword Entry", Representations 112 (University of California Press, 2010). I am indebted to these authors for the above information.
} 
and reading. He conceived of what he called 'forms of life' not as a moral world view, but as a set of social techniques and practices that facilitate congenial social life with minimal conflict. Another popular book in pre-war Vienna was Eduard Spranger's Lebensformen (1914; the English translation was entitled Types of Men). Spranger employed the term 'forms of life' to signify ideal types of human castes of mind, identifying six such temperaments: theoretical, economic, aesthetic, social, religious and ambition for power. Oswald Spengler, in The Decline of the West (1918/23) depicted human civilizations as akin to biological forms of life, with a distinctive lifecycle. And the Dutch historian of ideas Johann Huizinga used the expression in the sub-title of his great book The $W$ aning of the Middle Ages: A Study of the Forms of Life, Thought, and Art in France and the Netherlands in the $14^{\text {th }}$ and $15^{\text {th }}$ Centuries (1919). Here it evidently signifies a way of living characteristic of a culture during a given epoch - the mores and morals, the social relationships and manners, the forms of private and public life.

So, there is no question but that the expressions 'Lebensform' and 'Form des Lebens' and their cognates were in the air in Austria and elsewhere in the first decades of the twentieth-century. We do not know, and probably never shall know, whether Wittgenstein's occasional use of these expressions was dependent in any significant way upon one of the authors of the above mentioned books. The only one we know he read and admired was Spengler's Decline of the West. But he surely did not require Spengler to give him this, by then altogether humdrum, word or phrase. Nor, for that matter, was Spengler's conception of historical laws congenial to Wittgenstein. Indeed, he criticized Spengler, not for his occasional use of 'Lebensform', but for his failure to see that he had not discovered a determinate super-biological life-cycle through which civilizations must, by the adamantine laws of history go, but rather adopted this form of representation by which to describe the historical developments of civilizations.

\section{2. 'Form of life' in the Investigations}

The expression 'form of life' (Lebensform) occurs in the Philosophical Investigations only three times: in $\$ 19, \$ 23$ and $\$ 241$. This makes it 
difficult to accept the suggestion that the idea of a form of life is of pivotal importance in the book. I shall argue that this is, in one sense, correct. The idea expressed by the first two occurrences had already been well-developed by von Humboldt. Though important, Wittgenstein adds nothing new to it. The third occurrence is original (to the best of my knowledge), but it is not the pivot upon which the book turns. In another sense, however, the general conception that underlies this very sparse invocation of the expression, and its links with other notions in Wittgenstein later philosophy and methodology, in particular language-game, following rules, and practice, are of capital importance. For it is an integral part of the revolution in philosophical thought that the Investigations was instigating. That revolution wars with the calculus conception of language and linguistic representation, the computational conception of thought and linguistic-understanding, the referential (or 'Augustinian') conception of word meaning and truthconditional conception of sentence meaning. These lay at the heart of the philosophy of the Tractatus (as well as the philosophies of Frege and Russell). Moreover, as I have argued elsewhere, ${ }^{2}$ the spirit of the Tractatus lay at the heart of the interpretational turn in philosophy of language and theories of meaning for natural languages engendered by Dummett and Davidson in the 1960s that lasted until the 1990s, just as it still informs possible world semantics and metaphysics to this day. Wittgenstein's aim was to undermine such conceptions of philosophy, philosophy of logic and language and to replace them with an anthropological and ethnological conception. According to the latter (which incidentally harmonizes 'in the large' with von Humboldt's observations on thought and language), language is not the totality of sentences that can be generated from a set of primitive indefinables, definitions, formation- and transformation-rules. It is rather an uncircumscribable motley of human activities, of the playing of language-games, in the medley of human life.

Investigations $\$ 19$ (a) runs thus:

${ }^{2}$ P. M. S. Hacker, Wittgenstein's Place in Twentieth Century Analytic Philosophy (Blackwell, Oxford, 1996), pp. 1f., 264-73. 
It is easy to imagine a language consisting only of orders and reports in battle. - Or a language consisting only of questions and expressions for answering Yes and No - and countless other things. - And to imagine a language is to imagine a form of life.

Investigations $\$ 23(\mathrm{a})$ - (b), which complements it, runs as follows

But how many kinds of sentence are there? Say assertion, question and command? - There are countless kinds; countless different kinds of use of all the things we call "signs", "words". "sentences". And this diversity is not something fixed, given once and for all; but new types of language, new language-games, as we may say, come into existence, and others become obsolete and get forgotten. (We can get a rough picture of this from the changes in mathematics.)

The word: "language-game" is used here to emphasize the fact that the speaking of language is part of an activity, or a form of life.

It is, I think, doubtful whether one can coherently imagine a language consisting only of orders and reports in battle, but no orders and reports before or after battle, and no orders and reports at home and in the fields. What would such a society look like (what weapons do they have, what armour or clothing? Do they make weapons together, but without orders and reports? Do they hunt together, but silently, with no communication? How do they teach this language? If 'Look out!' is apt in battle, why not when hunting? If 'Do what I am doing!' is an intelligible instruction in battle, why not when cooking at home. And so forth. It is none too easy to imagine such a language, any more than it is easy to imagine language-game (2) as a complete primitive language. I don't think that this weakness matters in the slightest. Wittgenstein did indeed, as he slightly feared (MS 165, 95, and also MS 136, 53a), make things too easy for himself in order to bring the points he wished to make into the spotlight. Enriching the tales would have been more convincing, but would not affect the points he wished to highlight.

Similarly, it is an unfortunate slip to answer the question 'How many kinds of sentence are there?' by saying that there are countless kinds of use of all the things we call 'signs', 'words', 'sentences'. For kinds of use of sentences are not kinds of sentences, and although sentences are signs and consist of words, 
there are both signs and words that are not sentences, and the uses of words and signs are not the same as the uses of sentences. The paragraph needed redrafting. But that is not difficult. Something like the following will, I think, do:

How many kinds of use of sentences are there? Say asserting, questioning and ordering? - There are countless kinds of use of things we call 'sentences'. There are also countless signs and words that are not sentences, but which have uses in sentences in language-games, and also sometimes as one word sentences ('Fire!', 'Help!'), or on their own (in shopping lists or word-games (Scrabble)).

Again, nothing turns on this minor slip, and it in no way mars the capital points that Wittgenstein wishes to make in this sequence of remarks from $\$ \$ 18-25$, in which the double occurrence of the phrase 'form of life' plays a crucial role. The points are four.

First, to undermine, or begin undermining, the idea that language has an essence, given by the general propositional form. In the penultimate cardinal proposition of the Tractatus Wittgenstein had asserted that the general propositional form is $[p$, $\xi, N(\xi)$ ] (TLP 6), which says that every proposition is a result of successive applications to elementary propositions of the operation $N(\xi)$, i.e. the operation of joint negation on a set of elementary propositions. So a language consists in the totality of propositions (TLP 4.001). But this is misguided. A language is an open-ended series of language-games integrated into the actions and lives of its speakers. To learn a language is to learn how to do things with words. It is to learn how to act and respond to circumstances and to others, not how to calculate or compute the meaning (truthconditions) of a sentence from the meaning of its constituents and their mode of combination.

Secondly, to undermine the idea, central to most conceptions of the proposition from Plato and Aristotle to Frege and Russell, that a proposition is necessarily complex, composed of subject term and predicate term, or argument-expression and function-name. But this idea is dogmatism. For we can readily imagine a language that consists of one word sentences that are not, in that language, elliptical for anything. Moreover, it is not true that the many-worded sentence is the minimal unit for the performance of speech-act 
even in our languages ('Hello', 'Hi', 'Ciao', 'Cheers', 'Tally-ho', 'Damn!').

Thirdly, to challenge the idea that the essence of a proposition is to describe. This too was a pivotal idea in the Tractatus, viz.: the general form of a proposition is: This is how things stand (TLP 4.5), which is the general form of a description. But the sentences of a language may be only imperative sentences, which are not used to describe how things are; or sentence-questions, which are not used to describe how things are either. Moreover, there are indefinitely many logically different kinds of description.

Fourthly and consequently, to undermine the thought that every sentence has a truth-value, if not in surface-grammar, then in depth-grammar as revealed by analysis. So an order really has the form 'Make it the case - that things are thus and so', a sentencequestion has the form 'Is it the case - that things are thus and so?', and an assertion has the form: 'It is the case - that things are thus and so'. So every sentence in a language has a truth-value bearing component, a 'sentence-radical'. But this is sheer dogmatism, motivated by the exigencies of the predicate-calculus and a conception of meaning in which the notions of truth and of truthconditions are pivotal. One might as well argue that every sentence of a language contains a question, on the grounds that every declarative sentence can be represented by a sentence-question followed by a Yes (PI \22).

To establish these fundamental points is the purpose of $\int \$ 18$ 25 , and it is in the context of this goal that we should see the employment of the phrase 'form of life'. It is used, in both occurrences, to emphasize the fact that, as Wittgenstein says quite explicitly, 'speaking a language is an activity' integrated into a way of living - a conception strikingly absent from the Tractatus, from the conceptions of language advanced by Frege and Russell, as well as from those of Carnap, Tarski and their followers, and from theorists of meaning for natural languages that dominated Anglophone philosophy in the final quarter of the twentiethcentury. Not 'In the beginning was the Word', Wittgenstein averred after 1931, but rather 'In the beginning was the deed'! 
$\$ 241$ is the third and last occurrence of 'Lebensform' in the Investigations. Its use here is more difficult to understand. It needs to be contextualized:

$\$ 240$ Disputes do not break out (among mathematicians, say) over the question of whether or not a rule has been followed. People don't come to blows over it for example. This belongs to the scaffolding from which our language operates (for example, yields descriptions).

$\$ 241$ "So you are saying that human agreement decides what is true and what is false?" - What is true or false is what human beings say; and it is in their language that human beings agree. This is agreement not in opinions, but rather in form of life.

$\$ 242$ It is not only agreement in definitions, but also, (odd as it may sound) agreement in judgements that is required for communication by means of language. This seems to abolish logic, but does not do so. - It is one thing to describe methods of measurement, and another to obtain and state results of measurement. But what we call "measuring" is in part determined by a certain constancy in results of measurement.

$\$ 19$ and $\$ 23$ were concerned with emphasizing that language is a form of activity integrated in a way of living, $\$ 242$ shifts focus. It is concerned with emphasizing the fact that the shared language of a community involves a deep and unquestioned agreement on the rules for the use of expressions of the language and on what counts as their correct use. It is obvious enough that in order for language to be used as a means of communication, there must be agreement on what the expressions of language mean. What an expression means is given by a definition. It is, as has been emphasized again and again in the book, given by explanations of meaning in general, and not only by analytic definitions. For any explanation of the meaning of a word is a rule for its use. But as the lengthy discussion of following a rule has laboured to make clear, to agree on a rule is to agree on what counts as accord with the rule. A rule is not a mere rule-formulation. For if a form of words is to express a rule at all, it has to be used as the expression of a rule. It has to have the role of a standard of correctness that not only guides conduct, in so far as it provides a reason for using the explanandum in such-andsuch a way, but also provides a measure by reference to which one can judge a use to be correct. So, for example, we may all agree that 
This $\$$ and here we point to a metre-ruler] is one metre long, but such an agreement amounts to nothing unless there is agreement on how to measure, i. e. that one lays the ruler alongside the measured object and reads off its length from the ruler in such-and-such a way. This is not an agreement in opinion. It is not an agreement on a matter of fact either. It is an agreement in concepts, hence an agreement in the use of a word. But that is already an agreement in action, an agreement in the way in which we go about doing things with words. In that sense, it is an agreement in form of life. But now $\$ 242$ takes us one step further. For it is not enough that there be an agreement in the method of measurement (i. e. agreement in sense), there must also be widespread agreement in the results of measurement (i. e. agreement in truth). Otherwise the agreement in definitions, i. e. agreement in the concepts we deploy, disintegrates. (If we all measured with rulers, but never got the same result, the practice of measuring would cease to exist.)

This conclusion is indeed important for the argument of the Investigations, for it welds together two central points that Wittgenstein has been elaborating throughout: first, that meaning is use, and secondly, that meaning is given by an explanation of meaning (which constitutes a rule for the use of the explanandum). For the problem that gave rise to the long examination of following rules was: how can the meaning both be the use (which as he quaintly puts it, 'is spread out over time') and also be something that can 'be grasped at a stroke' when given by an explanation of meaning. How is the internal relation between a rule and its correct application (its application in accordance with the rule) forged? Famously, his answer is: by the practice, by the regular activity of using the word in the stream of life, by agreement in its use and in what is accepted as correct use. And that is an agreement in form of life.

\section{3. 'Form of life' elsewhere in Wittgenstein's writings}

In Philosophy of Psychology - a Fragment, $\ 1$ runs as follows:

One can imagine an animal angry, fearful, sad, joyful, startled. But hopeful? And why not? 
A dog believes his master is at the door. But can he also believe that his master will come the day after tomorrow? - And what can he not do here? - How do I do it? - What answer am I supposed to give to this?

Can only those hope who can talk? Only those who have mastered the use of a language. That is to say, the manifestations of hope are modifications of this complicated form of life. (If a concept points to a characteristic of human hand writing, it has no application to beings that do not write.)

This passage has occasioned puzzlement. Perhaps a dog cannot now hope for a bone next Christmas Day, but why can it not be said to hope for one now? Surely when feeding time arrives and its master goes to the fridge to get the tin of dog food, and the dog looks up beseechingly, wagging its tail. It not only believes that it is about to be fed, it also hopes to be fed, in as much as it expects something it finds good? Why should such a primitive form of hope not be as possible for a dog as is the primitive belief? Why should hope have application only to those who have mastered a language? Why need we appeal to the complicated form of life of a language-user?

The answer is clear if we reflect not on the familiar phenomenon of the eagerly awaiting dog, wagging its tail in enthusiastic anticipation, but on the use of the verb 'to hope'. (One cannot read concepts off phenomena.) One cannot hope for something one knows to be impossible - that is to say, there is no such thing as hoping for the impossible. If someone were to say that he hopes to meet Julius Caesar tomorrow, or hopes to grow younger every day, we would not understand what he is trying to say. Nor can one hope for something inevitable or necessary. If someone were to say that he hopes that this week Tuesday will be followed by Wednesday, or that he hopes to die someday, we should be equally puzzled. "You don't have to hope that", we might jokingly reply. In short, the conceptual space for hope lies within the boundaries of what is understood to be possible, and neither inevitable nor impossible. Consequently, for us correctly to describe a being as hoping for something, it must be a languageuser. For in order to hope, one must grasp the logical constraints on the objects of hope - that although one may fancifully wish to 
live forever, one cannot intelligibly hope to do so. For the manifestations of hope are not anticipatory tail-wagging or (in the case of the cat) purring, but rather the behaviour of a language-user who has mastered the use of the verb 'to hope' and can (if unimpeded) say "I hope", and not say such things as "I hope that this week Wednesday will follow Tuesday". So, in PPF \$1, the notion of a form of life is employed in a very general sense to signify the endlessly complex ways of living of language-using creatures in which the use of language is, and is integrated with, action.

Philosophy of Psychology - a Fragment, \$345 remarks: "What has to be accepted, the given is - one might say - forms of life". This plural form of the expression is in harmony with Investigations $\$ 19$, which suggested that different languages involve different forms of human life. The multiplicity of human forms of life is confirmed by MS 160, 51, where the question: "How is it that we agree in our applications of rules?" is answered: "Through training, drill and the forms of our lives. This involves not only a consensus of opinions but of forms of life." In the Blue Book, Wittgenstein said: "Imagine a use of language (a culture) in which ..." and again "imagine a language (and that means again a culture) in which ..." (BB 134). In short, human beings in different epochs, in different cultures, have different forms of life. Different educations, interests and concerns, languages, different human relations and relations to nature and the world constitute distinct forms of life. For different cultures form different conceptual structures, adopt distinctive forms and norms of representation, limited only by the vague boundaries of the concept of a form of representation or a language. Of course, in advance of a particular question and a specific context it would be quite pointless to draw hard and fast distinctions between what counts as the same and what as a different form of life. Did the Elizabethans share our form of life? Surely not, despite the fact that they spoke the same language as we do. Do all the English speaking peoples share a common form of life? Do bi-lingual peoples share two different forms of life? There can be no context-free answer to such questions. Nor does Wittgenstein need to answer them for his purposes, for he is not engaged in sociology or anthropology. What he is concerned with is 
the fact that a language is embedded in, and partly constitutive of, a way of living. To grapple with questions in philosophy of language, we must not conceive of languages as calculi. We must not think of understanding a language as mastery of a calculus, but rather as mastery of complex interlocking language-games. Nor should we view understanding the speech of others as a computational process of deriving the meaning of what they say from the meanings of the words they utter and their mode of combination in accordance with the rules of a calculus of language. It is noteworthy that in a different draft of PPF \$335, Wittgenstein wrote:

Instead of the unanalysable, specific, indefinable: the fact that we act in such-and-such ways, e.g. punish certain actions, establish the state of affairs thus-and-so, give orders, render accounts, describe colours, take an interest in others' feelings. What has to be accepted, the given - it might be said - are facts of living. (RPP I \$630)

So far, so (fairly) plain sailing. There are a few further striking and perhaps puzzling remarks in the manuscripts. In MS 137, 59a, we find the following remark about pretending:

So how does it begin? The child cries and no one speaks of pretence// possible pretence. Were something to look like pretence, it would be an animal pretence, a form of life. // an instinctive action. //

Then sometime something happens at which we think of pretence. It is perhaps a primitive pretending. But one doesn't yet know whether one can really call it so. It is connected with the development of the child's 'abilities'. Until one has observed a certain course of actions, one still doesn't know what he is really able to do. (..........) There is here a certain conceptual indeterminacy: "the beginning of his practice [Gepflogenheit]". ${ }^{3}$ - Only in a particular way of living [Lebensweise] // practice of living [Lebensgepflogenheit] // does one call it...

The theme is clear enough: at what point in the behavioural development of a child can one start speaking of its pretending something. The meaning of the sequence of dots in parenthesis is

\footnotetext{
${ }^{3}$ 'Gepflogenheit' means custom or habit. This sounds very stilted in English. Since it is evident that Wittgenstein is thinking of a regularity, and his question is "When does one speak of 'the beginning of a regularity'?", I have preferred to translate the word, in this context, as 'practice'.
} 
made clear in Wittgenstein's Brown Book discussion of which is the last dot of the close sequence of dots and the first of the spaced sequence: '..........' or, if these are holes in the revolving disc of a siren at which we first hear a low pitch tone and then a high pitch one, at what point does the tone of the low pitch end and the tone of the high pitch begin ( $\mathrm{BrB}$ 121)? There is no answer. Similarly, one has to observe a sequence of the child's behaviour before pretence can be identified and there is no determinate point in the sequence at which this is possible. The expression 'form of life' here appears to signify no more than a form of animal behaviour. For the behaviour of some ground-nesting birds that draw a snake away from their nest by feigning a broken wing cannot be said to be pretence in the sense in which human beings pretend.

In Wittgenstein's notes entitled "Cause and Effect: Intuitive Awareness", p. 397, ${ }^{4}$ he remarked, apropos the priority of certainty over doubt:

The primitive form of the language game is certainty, not uncertainty. For uncertainty could never lead to action.

I want to say: it is characteristic of our language that the foundation on which it grows consists in steady [firm] forms of life [Lebensformen], regular ways of acting.

Its function is determined above all by action, which it accompanies.

We have an idea of which ways of living are primitive, and which could only have developed out of these. We believe the simplest plough existed before the complicated one.

The simple form (and that is the prototype) of the cause-effect game is determining the cause, not doubting.

Here it is evident that the plural Lebensformen is being used to signify regular ways of living, entrenched practices that are not called into doubt.

\footnotetext{
${ }^{4}$ Repr. in J. Klagge and A. Nordman, Ludwig Wittgenstein: Philosophical Occasions 1912-51 (Hackett, Indianapolis, 1993), pp. 370-426.
} 
This theme is resumed, in altered form, in On Certainty, many years later. Discussing one use of 'I know', when my ability to recognize and name things is being tested, Wittgenstein notes that I might say 'I know that's a chair'. It would be wrong to say 'I believe ...', since that would imply my readiness for my statement to be tested. 'I know' in this context implies that I would be bewildered if what I said was not confirmed. My 'knowing' here consists in my not understanding where a doubt could get a foothold. 'I know' expresses comfortable certainty. In $\$ \int 358-9$ he adds:

Now I would like to regard this certainty not as something akin to hastiness or superficiality, but as a form of life. (That is very badly expressed and probably badly thought as well.)

This is, indeed, rather badly expressed, for the expression 'form of life' obscures rather than reveals the point, which is indeed much better expressed in \$359:

But that means I want to conceive it as something that lies beyond being justified or unjustified; as it were, as something animal.

A further, more peculiar, passage is to be found in MS 127, 128:

Even the devil in hell has a form of life; and the world would not be complete without it.

It is very obscure what this is supposed to mean. Perhaps that 'evil be thou my good' too is a way of living, and without it there would be an unrealized possibility in the world. This is indeed a theme of Milton's Paradise Lost, Book I:

To do ought good never will be our task,

But ever to do ill our sole delight,

As being the contrary to his high will

Whom we resist. If then his Providence

Out of our evil seek to bring forth good,

Our labour must be to pervert that end,

And out of good still to find means of evil; 
Is this what Wittgenstein had in mind? Perhaps he would have said that the Nazis too adopted a certain form of life. Be this as it may, this use of the term 'form of life' adds nothing to our reflections.

There are a few further occurrences of the phrase and its cognates in the MSS, but none add anything further.

\section{Misunderstandings rectified}

Wittgenstein's use of the term 'form of life' was sprung onto the philosophical audience of the Anglophone philosophical world in 1953 without any introduction. Few knew anything of the background use of the term Lebensform and its cognates in German and Austrian culture. Moreover, the Nachlass became available only slowly and most commentators had no chance of examining the use of these phrases in Wittgenstein's manuscripts and typescripts. It is small wonder that the phrase 'form of life' gave rise to different interpretations. ${ }^{5}$

(i) Wittgenstein's concept of a form of life is predominantly a biological concept. There is only one buman form of life, which characterizes our species and reflects our biological nature.

(ii) A complementary suggestion is that other forms of life would be unintelligible to us. 'If a lion could talk, we wouldn't be able to understand it' (PPF \$327) - and not because it would be speaking Swahili! Humanoids who reacted in fundamentally different ways from us, for example, who, like the cat, looked at the pointing finger rather than in the direction indicated, would be different kinds of creatures from us. Creatures who found it 'natural' to continue the series ' $2,4,6,8,10, \ldots$ ' beyond ' 1000 ' with '1004, 1008, ...' would find it impossible to enter into significant discourse with us. Their language-games would be impenetrable to us (cf. Z \$390).

(iii) Although we can imagine other forms of life, and imagine such creatures forming concepts for themselves, their concepts would be strictly unimaginable to us. (And this is why, it was sometimes

\footnotetext{
${ }^{5}$ The following remarks are derived from the discussion in G. P. Baker and P. M. S. Hacker, Wittgenstein: Rules, Grammar and Necessity, extensively revised $2^{\text {nd }}$ edition (WileyBlackwell, Oxford, 2009).
} 
held, Wittgenstein's attempted descriptions of such concepts collapse, e.g. the wood-sellers' concept of quantity and value (RFM 93f.), or the concept of length possessed by the users of elastic rulers (RFM 38f.).) This too, was held to rule out the view that our concepts, our rules for the use of expressions, are conventional. For, it is claimed, given our nature, we could not have significantly different ones.

(iv) The remark that human beings agree in the language they use, not in opinions but in form of life (PI \$241), has been taken to allude to our common 'natural reactions', or those elemental human practices the engaging in which makes us human. These are 'facts of human natural history' and they are prior to all conventions. Convention rests upon and presupposes such 'ways of going on' that are natural to us, inevitable for us. So, again, Wittgenstein has been held to have reached the conclusion that convention is a relatively superficial business. Philosophical profundity comes from delving beneath the superficial layer of convention to underlying facts of natural history that allegedly determine and characterize our form of life.

It should be clear from the discussion so far that these interpretations (mostly advanced by American philosophers) are awry. A few points are worth highlighting.

First, although it is correct that Wittgenstein contrasts the form of life of language-users with the ways in which other creatures that do not speak a language live, that does not mean that he thinks that there is only one human form of life. On the contrary, he is inclined to think of different languages as integrated into different ways of living, and to link the notion of a form of life to a culture. So the notion of a form of life is patently not predominantly a biological one.

A corollary of this is that the patterns of behaviour and behavioural regularities that Wittgenstein associates with a form of life are not uniformly biological, species-specific propensities. There is no biological naturalness in continuing the series of natural numbers as we do. Some societies rested satisfied with " $1,2,3,4,5$, many", and that too is a number system. It is natural, culturally natural, for us to count " $1,2,3, \ldots$ 1001, 1002, 1003, ... 100, 001, 
$100,002,100,003, \ldots$,.. But not for all people at all times and places. It is natural for $u s$, after we have been introduced to signed integers, to count backward thus " $+4,+3,+2,+1,0,-1,-2 .-3,-4, \ldots$ ", but not for others in earlier times who were familiar only with natural numbers.

Secondly, far from other conceptual structures being unintelligible to us, a little imagination can render them natural.

If you believe that our concepts are the right ones, the ones suited to intelligent human beings, that anyone with different ones would not realize something that we realize, then imagine certain general facts of nature different from the way they are, and conceptual structures different from our own will appear natural to you. (RPP I §48; cf. PPF \$366)

It is a mistake to suppose that Wittgenstein was arguing that our conceptual structures strike us as necessary because of our nature. A fortiori he was not suggesting that other conceptual structures unavoidably strike us as incoherent, are unintelligible or inaccessible to us. Necessity does not enter the domain of conceptformation. For grammar owes no homage to reality. It is, in this sense, autonomous. It does not reflect objective necessities. On the contrary, it determines what we conceive of as necessary. We can understand different colour geometries. We can understand different number systems. Despite philosophers' qualms about the intelligibility of measuring with elastic rulers, we can readily understand it given an appropriate stage-setting. After all, we use elastic rulers ourselves all the time - in the fluctuating exchange rates of foreign currencies.

Thirdly, Wittgenstein's concept of the 'natural history of man' is predominantly anthropological. What interests him will hardly be found, as it were, in the Natural History Museum (Department of Human Biology), but in the Ethnological Museum of Mankind. "Giving orders, asking questions, telling stories, having a chat, are as much a part of our natural history as walking, eating, drinking, playing" (PI \$25). Measuring in all its forms is part of human natural history, and a description of its varieties will make the concepts of measuring, exactness, etc. intelligible to us in all their variations (RPP I \$1109). One can give an ethnological account of the human 
institution of measuring with rulers and with the scale of feet and inches (RFM 356). Mathematics is an anthropological phenomenon (RFM 399). Working through proofs (hardly a feature of human biology) and accepting them is 'use and custom among us, or a fact of our natural history' (RFM 61). And finally, logic too belongs to the natural history of man (RFM 352f.); not to be sure, the propositions of logic, but rather that we use these propositions as we do, that we mould our concepts thus, etc. - that is a feature of our natural history. In short, the natural history of man is the history of a convention-forming, rule-following, concept-exercising, languageusing animal - a cultural animal. And it is important for philosophers to remember these very general facts.

Fourthly, if Wittgenstein's conception of human nature is not predominantly a biological one, then a fortiori his concept of a form of life is not primarily biological, but cultural. There is no uniquely human form of life, characteristic of the species - rather there are multiple human forms of life, characterized by different languages, and characteristic of different cultures and epochs.

To conclude: the expression 'form of life' plays a very small role in Wittgenstein's later philosophy. No aura or mystique should be allowed to attach itself to his notion of a form of life. In itself it is of no great moment. What is of great moment is the larger body of thought of which the concept of a form of life is merely a surface ornament. That larger body of thought is the ethnological conception of language as a form of activity embedded in the ways of living of a language-using community. That activity is normative, i. e. rule-governed - but not in the manner of a calculus; rather in the manner of a game. The rules for the use of words and symbols are given by explanations of meaning, including definitions (no matter whether analytic definition, ostensive explanations, contextual paraphrastic definitions, or family-resemblance explanations). But for there to be rules at all, there must be agreed ways of employing-rule formulations as guides for the application of the expressions the meaning of which they explain, and as justifications of the applications. What welds a rule to its applications (its extension) is the practice of going by it. This is an agreement in a form of life, involving a consensus concerning what 
counts as applying the rule correctly. That in turn demands a widespread if indeterminate consensus in judgements. This very general conception of language and its use, of concept-formation and application, informs Wittgenstein's anthropological approach to philosophy in general and to the philosophy of language, logic, and mathematics, in particular.

\section{References}

Baker G. P., \& Hacker P. M. S., 2009. Wittgenstein: Rules, Grammar and

Necessity, extensively revised $2^{\text {nd }}$ edition. Oxford: Wiley-Blackwell.

Helmreich S. \& Roosth S., 2010. "Life Forms: a Keyword Entry" In:

Representations 112, pp. 27-53.

Huizinga, J., 2009 (1919). The Waning of the Middle Ages: A Study of the Forms of

Life, Thought, and Art in France and the Netherlands in the $14^{\text {th }}$ and $15^{\text {th }}$

Centuries. Oxford: Benediction Classics.

Padilla Gálvez, J. \& Gaffal. M., eds. 2011. Forms of Life and Language Games.

Heusenstamm: Ontos Verlag.

Wittgenstein, L., 1967. Zettel. Eds. G.E.M. Anscombe \& G.H. von Wright.

Berkeley: Basil Blackwell.

Wittgenstein, L., 1969. The Blue and Brown Books. Oxford: Blackwell.

Wittgenstein, L., 1975. On Certainty. Oxford: Blackwell.

Wittgenstein, L., 1978. Remarks on the Foundations of Mathematics. Oxford:

Blackwell [RFM]

Wittgenstein, L., 1980. Remarks on the Philosophy of Psychology I. Oxford:

Blackwell [RPPI]

Wittgenstein, L. 1993. "Cause and Effect: Intuitive Awareness", In: J. Klagge

and A. Nordman (eds.): Ludwig Wittgenstein: Philosophical Occasions 1912-

51. Indianapolis: Hackett, pp. 370-426.

Wittgenstein, L., 2000. Wittgenstein's Nachlass. The Bergen Electronic Edition.

Oxford: Oxford University Press [BEE]

Wittgenstein, L., 2009. Philosophical Investigations. Transl. E. Anscombe, P.M.S.

Hacker and J. Schulte. Rev. $4^{\text {th }}$ Ed. Oxford: Wiley-Blackwell [PI, PPF]

\section{Biographical Note}

P. M. S. Hacker is a professor of philosophy at the University of Kent and an emeritus Fellow of St John's College, Oxford. He is 
author of more than twenty books and over one hundred and fifty papers. His main interests concern the philosophy of Wittgenstein, the history of analytic philosophy, philosophy of language and philosophy of psychology, and philosophy and cognitive neuroscience. He is currently completing a trilogy on human nature, the first volume of which was Human Nature: the Categorial Framework (2007), the second The Intellectual Powers: a Study of Human Nature (2013), and the final volume of which will be The Passions: a Study of Human Nature. 